\title{
The Developminent of Interactional Competence of EFL Learners
}

\author{
Perwi Darmajanti \\ Politeknik Perkapalan Negeri Surabaya \\ Indonesia \\ perwi.ppns@gmail.com
}

\begin{abstract}
The communicative approach has been widely adopted in EFL teaching practice. Most foreign language educators have readily embraced the communicative objective as the principle underlying teaching and learning activities in today classrooms. Concerning over the development of communicative competence, the present teaching of spoken English is still regarded unsuccessful, following complaints from stake holders because many graduates are still lack of foreign language communication skill to join in transcultural and world society. This paper reported a study of classroom interaction among Indonesian adult learners and native speakers of English. The study focused on the interactional competence of the learners. This is due to the importance of interactional competence in communicative competence development. Qualitative research was conducted by using questionnaires, interviewing and observing the activities in the classroom. The objective of the research is limited to find out how students manage communication problems with native speakers of English. The communication breakdowns which happened in the interaction might be influenced by multiple factors. The findings showed that language proficiency, attitude towards English, communication strategy and cultural aspects contribute influential factors to the success of oral communication and the development of intercultural competence. These factors gain less attention to be involved in foreign language teaching and learning as many CLT implementations are reported. Results of the research are expected to give possible solution of communication problems and to increase effectiveness of the application which are also preparing learners to involve in bidirectional or multi-directional conversation which are naturally practiced in the real life.
\end{abstract}

Keywords-strategic competence, communication strategy, interactional competence

\section{INTRODUCTION}

The need of excellent communicative skills in foreign language is urgent. Even now, communicative competence has become an essential skill in this 21th century, and English has been a central language for global communication. It leads to put successful learning of communicative English language skills, especially speaking skills, to be an important goal of language teaching. It can generally be understood that the objective of teaching and learning English is to enable the students to be able to communicate and interact with other people in the global society. Reference [15] Even most students feel that being able to communicate orally is ultimate in a foreign language learning.

Reference [20] Although many learners put priority on oral skill of language, but some facts prove that speaking skills development is less prioritized. Complaints on lack of speaking skill of students and graduates happen in many places in the world. Luo described that most Chinese students could not orally communicate with others in English although they had learnt English for years. Reference [22] In Lithuania the problems in learning good speaking skills and low English proficiency of schools' graduate happens every year. The condition in Indonesia is almost the same that a great number of learners face a lot of difficulties in using English orally and spontaneously although Reference [17] they are motivated enough to increase their communication competence.. Furthermore, Reference [38]
Widiati and Cahyono found that Indonesian EFL learners were eager to reach fluency as the result of foreign language learning.

For decades the popular Communicative Language Teaching (CLT) Reference [33] encourages the learners to communicate in target language to improve their communication competence. However, the expectation that learners will have a high level of communicative competence and eventually they will use target language willingly and effectively may be hardly reached due to nature of human as Reference [12] Dörnyei claims that it is common among people to avoid communicating in target language though they could be communicatively competent. This reluctance shows a reason of low communicative competence of EFL learners.

On the other hand, Reference [21] different from the model of communicative competence, interactional competence supports naturalistic interaction using the target language. It serves as a link that connects any linguistic or interactional resources which enables a person to communicate in a given context. This concept covers not only the language aspects which include register and modes of meaning, but also the interaction aspects such as sequential organization, turn taking and repair.

Considering both conditions, it needs to find out how learners employ their communicative competence in natural and spontaneous speaking task with native speakers of the target language. This context requires learners to use their communicative competence and interactional competence at the same time. If there is an indication to avoid communicating in target language, but there is also a need to interact using target language, learners should put the need to interact first. It will push them to communicate in the target language and put their reluctance to use the target language aside.

For this reason, the aim of this study was to investigate the development of interactional competence in English among Indonesian learners. Bearing this purpose in mind, the present study examined how attitude towards international community, motivation to learn English, linguistic self-confidence and their communication strategies may be influential in their performance in target language.

\section{REVIEW OF LITERATURE}

Communicative Language Teaching (CLT) is the latest trend in language teaching and learning. This leads language teachers to shift their attention from prioritizing perfect grammatical and linguistic competence to communicative use of that language. It can be said that being proficient in one language means being able to communicate in that language fluently rather than to master the structures. Communicative use of a language is usually performed orally because language is a mean of communication; communicating facts, ideas and thoughts are delivered using language. Reference [32] Richard even explained that one of the goals of CLT is to develop speaking fluency in language use.

The development of communicative competence requires the development of four aspects of communicative competence as Reference [7] Canale and Swain divided communicative competence into linguistic competence (knowledge of linguistic forms), sociolinguistic competence (the ability to use language appropriately in contexts), discourse competence (coherence and cohesion), and strategic competence (knowledge of verbal and non-verbal communication strategies). The theory implies that linguistic or grammatical competence alone is not enough to be able to communicate using language in a given cultural social set up. 
Focusing on strategic competence, it as the ability to express oneself to face difficulties or limited language knowledge. Furthermore, Reference [7] it is defined as 'verbal and non-verbal communication strategies that may be called into action to compensate for breakdowns in communication due to performance variables or to insufficient competence'. Reference [29] It is regarded a promising breakthrough in solving the problem of fluency in speaking foreign language. The notion of strategic competence is then developed by Swain by including communication strategies that may be called into action either to enhance the effectiveness of communication or to compensate for communication breakdowns. In other words, strategic competence functions to increase communication performance. Reference [40] This is similar with definition from Yule and Tarone about strategic competence which is described as an ability to select an effective means of performing a communication act that enables the listener or reader to identify the intended referent.

Reference [7] Canale and Swain and Reference [1] Bachman mentioned about meaning and communication strategies in the concept of strategic competence. They put priority on the role of meaning in communication. Supporting the concept, Reference [28;27] Bialystok and Fröhlich, and Paribakht, prove that learners of second language use communication strategies in getting their meaning across when they face lexical problems. Dealing with communication, Reference [1] Bachman mentioned that strategic competence is to relate language competence to the language user's knowledge of the world and to the features of the situation. Finally, Reference [29] Paribakht defined communication strategies as underlying elements in speakers' attempt to transmit their thought to their interlocutor.

Reference [7] Communication strategies which are related to how speakers of the language productively express meaning or deliver messages to others are usually used by second language learners to attain a degree of communicative effectiveness beyond their current linguistic knowledge. Related to fluency development, Reference [27] the ability to use a variety of communication strategy is influential. Furthermore, Reference [16] proved that students' insufficincy of linguistic competence leads them to seek alternative ways to convey meaning. While struggling to cope with communication problems, students paid less attention to the problem of accuracy. However, it is worth noting that most of them did not abandon their attempts to communicate, indicating a strong intention to achieve communication goals.

Reference [35] Communication which happened in the interaction of human is affected by several cultural assumptions about the purpose of particular interaction and expected outcomes of encounters. He emphasized the importance of culture knowledge to support oral communication skill development and communication. This is the underlying theory to learn culture of the foreign language because the lack of knowledge of culture could be a problem in foreign language communication. Reference [19;21;13] The involvement of culture in language learning is due to the function of language which is more than a tool for communication. It also represents social and cultural background. Therefore, learning the linguistic aspect of a target language cannot successfully engage learners into real-life communication in the target culture. Engagement into real-life communication in the target language can be achieved by learning not only linguistic aspect of the language but also the social and cultural background.

Various scholars are interested in investigating interactional competence, as compared to communicative competence. Many have voiced out their dissatisfaction on the model of communicative competence, and suggested that ESL practitioners look at interactional competence and how it is employed in naturalistic interaction such as the classroom. Theory is defined as "the knowledge that participants bring to and realize in interaction and the knowledge of how such knowledge is acquired.

The theory is based on two notions. First of them is co-construction introduced by Jacoby and Ochs and described as "the joint creation of a form, interpretation, stance, action, activity, identity, institution, skill, ideology, emotion, or other culturally meaningful activity". Young emphasizes that in this theory second language knowledge is considered to exist not within the mind-brain of a single participant; rather it is considered to be jointly constructed in interaction. The important fact emphasis is that the co-construction does not automatically imply "affiliative or supportive interactions". The second notion of interactional competence theory is based on a concept that competence is local to specific instances of interaction, which are termed by Hall as interactive practices. The talk is comprised of interactive practices, structured moments of face-to-face interaction - differently enacted and differently valued - whereby individuals come together to create, articulate, and manage their valued resources". The first notion of interactional competence use the concept of strategic competence in their implementation, while the second notion supports Reference [1] Bachman's concept of language competence which then also takes roles in developing strategic competence.

According to Hall "our becoming participants involves three processes: the discovery (other- and self-guided) of interactive patterns in the practices in which we engage with others; observation and reflection on others' participatory moves and responses to these moves; and our own active construction of responses to these patterns". Thus, we can compare it to the assessment component of strategic competence which is referred to by Bachman Reference [1] as taking stock of what is needed, what one has to work with, and how well one has done. It provides a means by which the individual relates their topical knowledge and language knowledge to the language use setting and tasks or to the testing situation and tasks as well as taking into consideration the individual's affective responses.

Considering the influence of culture in development of interaction competence of EFL learners, it is better to learn how it is developed among Asian students. Reference [39] Yagi reported the development in Japanese context that ESL students were able to learn through their repeated participation in the same situated practice, even with no explicit feedback from the researcher or an instructor. In the study, language learning was possibly by the opportunities for the learners to interact with more competent participants. However, the degree of competence and learning varied from student to student. It is possible that some forms or structures had been studied before the interactions, but it was through these moments of meaning negotiation that these forms were brought to use in order to achieve specific goals, and thus their interactional competence could be improved. Reference [11] Donald reported in Taiwanese context where the instructor played a very important role in developing learners' interactional competence which is shown in the classroom interaction. Reference [24] Krishnasamy made a research in Malaysian context. He mentioned that his research was very much focused on the different aspects of communication, especially the verbal and the nonverbal aspects of communication, students' negotiating skills and any particular aspects that are perceived to influence the interaction process. For instance, Malaysian English or the mother tongue influence was evident and used as a linguistic resource when something needed to be expressed in relation to the task.

Following to those research, Reference [36] Tecedor supported Reference [39] Yagi's findings that although subject to great individual variability and not always following nativelike standards, English native speakers in the early stages of learning Spanish are able to express varying degrees of alignment in conversations with a peer of a similar proficiency level. As they strive to create a sphere of mutual understanding, they test different options from their linguistic repertoire and learn not only from their own attempts but also from those of their interlocutor. These results suggest that repeated engagement in interactional practice does provide the linguistic, social, and pedagogical affordances learners need to develop the interactional skills that will serve them well not only to build confidence and competence in the classroom learning context, but also hopefully in the world outside the classroom.

\section{METHODOLOGY}

\section{A. Research Design}

Considering the research problem, this research used qualitative approach. Qualitative research approach, as it is used to explore the problem, to identify kinds of cognitive and affective factors to participant's interactional competence development. The method is employed to gain deeper perspective of the phenomena. Investigating interaction development factors requires a comprehensive exploration to collect data because they include some psychological factors behind the actual linguistic performance. The data cannot be 
presented in terms of quantitative quality although some of the quality are measured by numbers.

\section{B. Participants and Setting}

The participants of the present study were 50 students of military based institute of technology. The students are officers of navy and air force, studying industrial engineering. All participants are male. Their age was between 25 and 35 . The participants had been studying for two years and had accomplished English course. Most participants are at elementary level of English proficiency which only $10 \%$ of them are at intermediate level.

The participants were in an English Program which involved United State Army Cadets as tutors. Their age was between 20 and 25. Some of the cadets are native speakers of English, and some of them are bilingual speakers of English and other language such as Spanish and Tagalog language of Phillipines.

\section{Instruments}

Questionnaire is used to gather data. Nakatani's “Oral Communication Strategy Inventory" (OCSI) is used in the questionnaire of communication strategy. The questionnaires of OCSI give representation of participants' choice of communication strategies. The questionnaires are also adjusted with the purposes of the research by adding some items of attitude and motivation. The influencing factors are explored through interview and observation to find out the explanation and/or correlation among variables.

\section{FINDINGS AND DISCUSSSION}

The findings of the study includes learners' attitude towards international community, motivation to learn English, linguistic self-confidence and the communication strategies usage. Those factors are considered influential in the development of interactional competence. And each factor may have influence to the other factors. For example, factor of attitude towards international community may determine motivation, self confidence and the choice of communication strategies to use. This section will describe the findings of the study which then it is followed by relevant discussion.

All participant of the study have positive attitude towards international community, although at different level. The leve of positivity increases when the participants were experienced of abroad assignment. They used to be assigned as United Nation Peace Keeper Officers which gave them access to interact and communicate with people of different countries. Their positive attitude is shown in their participation in learning activity.

The participation can be divided into two kinds: active and passive ones. The active participation is indicated by answering and responding voluntarily in the conversation. The passive participation did not mean ignoring the class, but waiting to be assigned by the tutor although the atmosphere of learning is relatively less formal. Only $20 \%$ of the participants responded actively, while the rest did passively.

Most participants involved passively in classroom activity because they perceived themselves to have low English proficiency. It made them less confidence to speak in order to respond to any given questions. The self-confidence of the learner increased when they were in small group of discussion. This was shown by increasing participation in the group activities.

Related to the cultural factors, there were gaps between the participants and the tutors. The gaps were shown on the sense of humor. The sense of humor of US cadets was differen from one of Indonesian officers. Although they had the same background of occupation, they laughed at different objects of their occupation. The US cadets made jokes on their uniforms while the Indonesian officers could not able to find the joke in the story. The Indonesian learners' lack in finding the joke was not influenced by their limited vocabulary. It was merely different cultural exposure.

The choice of words in vocabulary games was also much influenced by the culture and the environment. The US cadets were more familiar with "boa" (a kind of giant snake of America Continent), "trousers", "brown", etc. Indonesian officers were less familiar with the words. They knew "phyton" better than "boa" in terms of giant snake. They knew "pants" better than "trousers". They said "chocolate" in spite of "brown". This shown that the natural environment and mother tongue influenced the choice of words
The native speakers found difficulty to understand some sentences produced by Indonesian learners. The difficulties were then solved by asking more information related to the sentence. An Indonesian learner made this sentence: "I go to school by bike which I ride". At glance, there is no grammatical mistake. But the native speaker said that people did not say the way the Indonesian learner said. He said that it should be "I ride my bike to school". There was different point of view towards the same fact which influenced to put the subject of the sentence.

\section{IMPLICATION TO TEACHING \\ SPEAKING}

The explanation above shows us that the teacher should pay attention to cultural factors influencing the way her students communicate. It cannot be justified only by the modern and updated teaching strategy because the trend of current learning is not teacher centered anymore, but that is one of student centered. It implies to the suggestion that influencing factors of learners' achievement must be considered and calculated carefully before determining how teaching speaking is delivered.

Teaching speaking should be developed more to increase the effectiveness of the strategy. As speaking is not only involving linguistic competence, teachers should also develop learners' strategic competence which is proven valuable in developing interactional competence, especially in Asian contexts. This also supports to the opinion that strategic competence is a breakthrough to cope limited linguistic competence and cultural factors.

\section{References}

[1] Bachman, L. 1990. Fundamental considerations in language testing. New York: Oxford University Press

[2] Bennett, Milton, J. 1998. Intercultural communication: A current perspective. In Milton J. Bennett (Ed.), Basic concepts of intercultural communication: Selected readings. Yarmouth, ME: Intercultural Press)

[3] Berns, Margie. (1990). Contexts of Competence: Social and Cultural Considerations in Communicative Language Teaching, New York: Springer Science+Business Media.

[4] Bongaerts,T., \& Poulisse, N. 1989. Communication strategies in Ll and L2: Same or dif ferent? Applied Linguistics. 10.

[5] Brown, H. Douglas. 2007. Principles of Languages Learning and Teaching: Fifth Edition. White Plains: Pearson Education, Inc.

[6] Byram, M. 1997. Teaching and Assessing Intercultural Communicative Competence. Clevedon, UK: Multilingual Matters.

[7] Canale, M and Swain, M. (1980). Theoretical Bases of Communicative Approaches to Second Language Teaching and Testing. Applied Linguistics

[8] Chambers, F. 1997. What do we mean by fluency? System, 25(4), 535-544.

[9] Chamot, A. 2005. Language learning strategy instruction: Current issues and research. Annual Review ofApplied Linguistics, 25, 112-130.

[10] Chomsky, N. (1965). Aspects of the theory Of syntax. Cambridge, MA: Massachusetts: Institute of Technology Press.

[11] Donald, Shane. 2015. A study of interactional competence in the Taiwanese English as a foreign language classroom context. Ph.D Thesis.

[12] Dörnyei, Zoltán and Thurrell, Sarah. 1991. Strategic competence and how to teach it. ELT Journal Volume 45/1 January 1991 C Oxford University Press. Retrieved from http://www.zoltandornyei.co.uk/uploads/1991dornyei-thurrell-eltj.pdf

[13] Faerch, C., \& Kasper, G. 1983. Plans and strategies in foreign language communication. In C. Faerch \& G. Kasper (Eds .),Strategies in interlanguage communication. London: Longman.

[14] Grabe, W , \& Kaplan, R. 1996. Theory and practice of writing. An applied linguistic perspective. Harlow, UK: Longman 
15] Graham, S. 2007. Developing Speaking Skills in the Modern Foreign Language, Practical Guide to Teaching Modern Foreign Language in the Secondary School. Oxon: Roult Ledge

[16] Huang, Chiu-Ping. 2010. Exploring Factors Affecting the Use of Oral Communication Strategies. Retrieved from

https://www.researchgate.net/publication/267959139 Exploring_Factors_Affecting_the_Use_of_Oral_Co mmunication_Strategies

[17] Huriyah. 2015. Implementing Speech Community Strategy to Enhance Students' English Speaking Ability. Indonesian EFL Journal Volume 1 Issue 2 .ISSN: 2460-0938; E-ISSN: 2460-2604|.

[18] Hymes, D. 1971. On Communicative Competence. In J. B. Pride \& J. Holmes, (Eds.), Sociolinguistics (pp. 53-73). Harmondsworth, England: Penguin Books.

[19] Hymes, D. 1972. On communicative competence. In . Pride \& . Holmes (Eds.), Sociolinguistics. Harmondsworth, UK: Penguin Books.

[20] Jabeen, Shazi S. 2014. Implementation of Communicative Approach. English Language Teaching Journal Vol. 7 No. 8, 2014, E-ISSN 19164750, Published by Canadian Center of Science and Education

[21] Johnson, M. 2004. A Philosophy of Second Language Acquisition. New Haven: Yale University Press.

[22] Kaminskiene, Ligija \& Kavaliauskiene, Galina. 2014, Attitudes to Improving Speaking Skills by Guided Individual Activities. Santalka: filoogija/Coactivity: Philoogy, Educology eISSN 2335-7711.

[23] Kaplan, R. 1966. Cultural thought patterns in intercultural education. Language Learning, 16

[24] Krishnasamy, Hariharan N. 2016. Investigating interactional competence using video recordings in ESL classrooms to enhance communication. American Institute of Physics Conference Proceedings.

[25] Lennon, P. 2000. The lexical element in spoken second language fluency. In H. Riggenbach (Ed.), Perspectives on fluency (pp. 25-42). Ann Arbor: University of Michigan Press.

[26] Liu, Lu. 2011. An International Graduate Student's ESL Learning Experience Beyond the Classroom. ESL Canada Journal/Revue TESL du Canada 91 vol. 29, no 1, winter 2011.

[27] Nakatani, Yasuo. 2006. Developing an Oral Communication Strategy Inventory, The Modern Language Journal, 90.

[28] Paribakht, T. 1985. Strategic communicative competence and language proficiency, Applied Linguistics 6, 132-146.

[29] Paribakht, T. (1986). On the Pedagogical Relevance of Strategic Competence, TESL Canada Journal/Revue TESL du Canada Vol.3, No.2, March 1986.

[30] Perrucci R., \& Hu, H. (1995). Satisfaction with social and educational experiences among international graduate students. Research in Higher Education

[31] Richards, Jack C \& Rodgers, Theodore S. 2001. Approaches and Methods in Language Teaching. Cambridge University Press. Retrieved from http://ebooks.cambridge.org/ebook.jsf?bid=CBO9780 511667305

[32] Richards, Jack C. (2006), Communicative Language Teaching Today, New York: Cambridge University Press

[33] Savignon, Sandra J. 2007. Beyond Communicative Language Teaching: What's ahead?. Journal of Pragmatics 39. Retrieved from www.sciencedirect.com

[34] Segalowitz, N. 2003. Automaticity and second language acquisition. In C. Doughty \& M. Long (Eds.), The handbook of second language acquisition. Oxford: Blackwell.

[35] Shumin, Kang. 1997. Factors to Consider: Developing Adult EFL Students' Speaking Abilities. E-USIA Forum Vol. 35. No.3 July-September 1997. Retrieved from dosfan.lib.uic.edu/usia/EUSIA/forum/Vols/Vol35/no3
[36] Tecedor, Marta. 2016. Beginning Learners' Development of Interactional Competence: Alignment Activity. Foreign Language Annals, Vol. 49, Iss. 1, pp. 23-41. (C) 2016 by American Council on the Teaching of Foreign Languages.

[37] Walter, T. 2004. Teaching English language learners: The how-to handbook. White Plains, NY: Longman.

[38]Widiati, Utami \& Cahyono, Bambang Yudi. 2006. The teaching of EFL speaking in the Indonesian context: the state of the art. Journal Bahasa dan Seni, Tahun 34, Nomor 2, Agustus 2006

[39] Yagi, Keita. The Development of Interactional Competence in a Situated Practice by Japanese Learners of English as a Second Language

[40]Yule , G., \& Tarone , E. (1990). Eliciting the performance of strategic competence. In R. Scarcella, E. , Andersen, \& S. Krashen (Eds.), Developing communicative competence in a second language. New York: Newbury House 